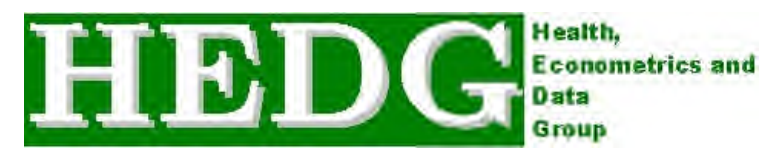

THE UNIVERSITY of Work

HEDG Working Paper 10/04

\title{
Conditional Cash Transfers to Improve Education and Health: An Ex ante Evaluation of Red de Proteccion Social, Nicaragua
}

\author{
Ranjeeta Thomas
}

March 2010 


\title{
Conditional Cash Transfers to Improve Education and Health: An Ex ante Evaluation of Red de Protección Social, Nicaragua
}

\author{
Ranjeeta Thomas *
}

October 21, 2010

\begin{abstract}
Using baseline data from from a randomized experiment, this paper applies a semi-parametric single index model to predict the ex ante impact of a conditional cash transfer in Nicaragua. It uses a behavioural model with a health production framework to estimate the impact on health related outcomes for children below 3 years. It validates the model with the results of the experiment and then simulates two alternate policy scenarios. The model performs well in predicting the health related outcomes and shows different results for the two sets of policy scenarios.
\end{abstract}

Keywords: ex ante evaluation, conditional cash transfers, single index models, education, health production function

JEL classification:I38, I20, I12, O12

\section{Introduction}

Millions of children under 5 years face risks to their development from poverty, poor nutrition and limited access to healthcare. Grantham-McGregor et al. (2007) estimate that the above risks prevent more than 200 million children under 5 years from reaching their potential in cognitive development. Poor nutrition, untreated infections and lack of growth monitoring can result in growth retardation and stunting. Evidence from several developing countries shows that these children are in turn less likely to enrol in school and perform as well as children not facing these risks (Moock \& Leslie 1986, Brooker et al. 1999, Glewwe et al. 2001). This lack of investment in human capital results in intergenerational transmission of poverty and poor health.

${ }^{*}$ I would like to thank Prof. Andrew M. Jones, Prof. Nigel Rice and the members of the Health Econometrics and Data Group (HEDG) at the University of York, UK for their comments. This paper uses data made available by the International Food Policy Research Institute (IFPRI). All errors remain my responsibility. Thomas: University of York, Department of Economics and Related Studies, Heslington, York YO105DD, rat503@york.ac.uk 
Early interventions that promote child development ameliorate the above risks and are critical to improving health outcomes and breaking the circle of poverty (Engle et al. 2007). To address the problem conditional cash transfer(CCT) programs have emerged as popular social protection schemes and are now implemented by many governments in Latin America and several parts of Africa. While these programs have largely focused on improving access to education for children, some programs have also implemented health components with a view to reducing current poverty while encouraging investment in human capital and health. Typically the health components of these programs look to improve access to preventive interventions and monitor child growth.

Evaluating the impact of these programs is critical to understanding their effectiveness in different settings. A few of the CCTs in Latin America were implemented as pilot randomized experiments. While these experiments provide the best estimate of the ex post treatment effect, they are limited in their application to exploring alternative policy scenarios or estimating the impact of expanding a pilot program. Such analyses require ex ante evaluations using behavioural models. Two approaches are available to carry out ex ante evaluations. The first approach relies on structural estimation of a dynamic behavioural model. Todd \& Wolpin (2006) and Attanasio et al. (2005) apply this approach to estimate a discrete choice dynamic programming model of education and fertility outcomes for the Progresa program in Mexico. More recently, building on the work by Ichimura \& Taber (2000), Todd \& Wolpin (Forthcoming) propose a second approach based on estimating reduced form equations using minimal assumptions of functional form and applying non-parametric estimation methods to compare predicted school enrolment outcomes with those of the experiment for the same program. The present paper extends their reduced form approach to test the feasibility of this approach in forecasting health related outcomes. For the health related outcomes it relies on a health production framework and considers the impact of the cash transfer on demand for immunizations and the take up of child health checks. The paper also carries out simulations of alternate policy scenarios.

The data used in this paper is from the Red de Protección Social CCT program in Nicaragua. The program was implemented in 2000 as a randomized social experiment and has two equally large cash transfer components, one for school enrolment and the second for food security and nutrition. The behavioural model reduced form (BMRF) approach used in this paper differs from Todd \& Wolpin (2006) and Attanasio et al. (2005) in that it does not estimate the structural parameters of the model. Instead it relies on variation in the observed policy variables, in this case school costs and full income, and models the reduced form demand equations for the outcome variables from an underlying static model. Identification in this approach requires the program to channel its influence solely through the budget constraint and the reduced form 
functions before and after the program remain the same. Empirically, the model is implemented using a semi-parametric single index model which relaxes the limitation on the number of exogenous variables possible in a fully non-parametric approach. The semi-parametric approach also allows for greater flexibility in capturing confounders.

The next section describes the RPS program in greater detail. Section 3 describes the theoretical model, section 4 discusses the empirical strategy, section 5 describes data and variables. Section 6 discusses the results of the ex ante evaluation and the simulations of alternate policy scenarios. Section 7 concludes.

\section{Background}

\subsection{CCTs and health services}

CCT programs are social protection programs aimed at breaking the intergenerational transmission of poverty and poor health. These programs offer cash transfers that can be spent without restrictions, however receiving the cash transfer is conditioned on altering certain behaviours - such as enrolment of children in school and investing in preventive health care for children. The goals are to simultaneously reduce poverty while encouraging investment in human capital. The cash transfers are a form of subsidy that reduce the financial barriers to accessing either education or health services. The level of services accessed by a household are driven by both demand and supply side factors, where on the demand side the level and frequency with which an individual or household accesses care depends on their level of informed decision making i.e - the ability with which they are able to identify being ill or the need for preventive care and the capacity to access and utilize care (Ensor \& Cooper 2004). CCT programs target these demand side barriers. Three assumptions underlie the health components of CCT programs (Glassman et al. 2007); the first, that poor households under-utilize health services, the second, that these families do not possess sufficient health education and knowledge about the benefits of accessing preventive care and third, in order for the transfer to have an impact receipt of the transfers must be conditioned on some health related behaviour altering requirement.

\subsection{Health care utilization and vaccinations}

Health services in a CCT program targeted at children are usually provided as a package of services with the cash transfer serving as an incentive to access the package. CCTs recognize the production of child health has several inputs, including maternal schooling and endowments (abilities of the mother, knowledge of 
nutrition and habits) and access to preventive care (Behrman \& Wolfe 1987). Embedding different outcomes in a package of services could increase demand for individual outcomes more than if they are provided as separate services as the marginal impact of one input may be higher when combined with the other relevant inputs (Strauss \& Thomas 2008).

One major outcome, that in most CCT programs is designed as an explicit conditionality, is health checks for children below 3 years. The use of health checks for children is an important input in overall health and development. Accessing these services is however closely associated with the level of education of the parents and the time and financial costs of accessing care. Thus, by making health checks for children a conditionality for the cash transfer, these programs look to minimize the impact of a family's socioeconomic status on child health seeking behaviour. Evidence from ex post evaluations of CCT programs from three Latin American countries - Honduras, Nicaragua and Colombia (see Glassman et al. (2007) for a summary) have shown significant increases in the number of children being taken to health clinics.

Vaccinations against preventable diseases such as measles, tetanus and whooping cough are the most costeffective of preventive health interventions (Miller \& Hinman 2004, Hadler 2004) and are provided within the package of services provided by CCTs. However, unlike health checks, they are rarely made an explicit conditionality and are typically provided under the general set of services provided at health checks. The $e x$ post evidence is limited due to the lack of complete data for the different vaccines that are given to achieve 'full immunization'. One exception is the RPS program in Nicaragua. The randomized evaluation (Barham \& Maluccio 2009) shows a 19 percentage point increase in full coverage as result of the program. Evidence from the Progresa program in Mexico and the CCT program in Honduras is limited to certain vaccines, but both find small but positive impacts.

\subsection{Red de Protección Social}

Red de Protección Social (RPS) was implemented in 2000 as a pilot randomized evaluation in 42 localities of six rural municipalities of Nicaragua. The pilot evaluation was maintained as an experiment for two years following which the initial control group was integrated with the treatment group and provided the cash transfers. The program was designed to target education of children in rural households and had two transfer components. The first was a school transfer component given conditional on all children in the household between the ages of 7-13 who have not completed grade 4 of primary school enrolling and maintaining $85 \%$ attendance. Independent of the school component the food security, health and nutrition transfer was provided directly to mother's of beneficiary housholds condtional on (1) bringing her children to scheduled 
preventive health checks, (2) attending bimonthly health education workshops and (3) adequate weight gain for children. Figure 1 presents a summary of the eligibility criteria and requirements for RPS.

The health services provided during the compulsory checks included growth monitoring, vaccinations and nutrition supplements for anaemia and anti-parasite medicines. Beneficiaries were required to use RPS trained and enlisted providers. However, there was a delay in expanding the government health services to meet the demand from the program and hence the health related conditionalities were not enforced during the first 8 months of the transfers. Thus for this period the food security/health transfer was an unconditional income transfer. Providers enlisted by RPS were paid to travel to program regions by the program operators to provide vaccinations and the additional health services in existing facilities or other community facilities. The required infrastructure and stock of medicines and vaccinations were monitored and provided at these facilities by the program operators.

The amounts of the transfer for each household included, the Córdoba 2000 equivalent of US\$224 for food security and US\$112 for the education component per year. In addition families also received a per child school supplies transfer of US\$21. Figure 2 shows the summary of the transfer amounts. Maluccio \& Flores (2005) estimate that the food transfer was approximately $13 \%$ of annual household expenditure and if families had only one school component eligible child, then they received an additional $8 \%$ of annual household expenditure.

\section{Theoretical Framework}

This paper focuses on empirically estimating and predicting health related outcomes under the RPS cash transfer program. It relies on a static behavioural model of infant health production (below 3 years) and school enrolment of school aged children (7-13 years).

Health of an infant is assumed to be produced by a production function specified as a function of health related consumption inputs, medical care inputs and a vector of household characteristics.

The health production function is:

$$
H_{i}=h\left(\mu \cdot E^{m}, M ; X_{h}\right)
$$

where $E^{m}$ is a binary indicator of attendance at the conditional educational workshops by the mother, $\mu$ represents consumption of nutritional food or other health inputs which is assumed to depend on the transfer received conditional on the mother attending the workshop. This term is set equal to zero in the pre-program situation as $E^{m}$ equals zero before the program. $M$ represents medical care inputs and $X_{h}$ represents a vector 


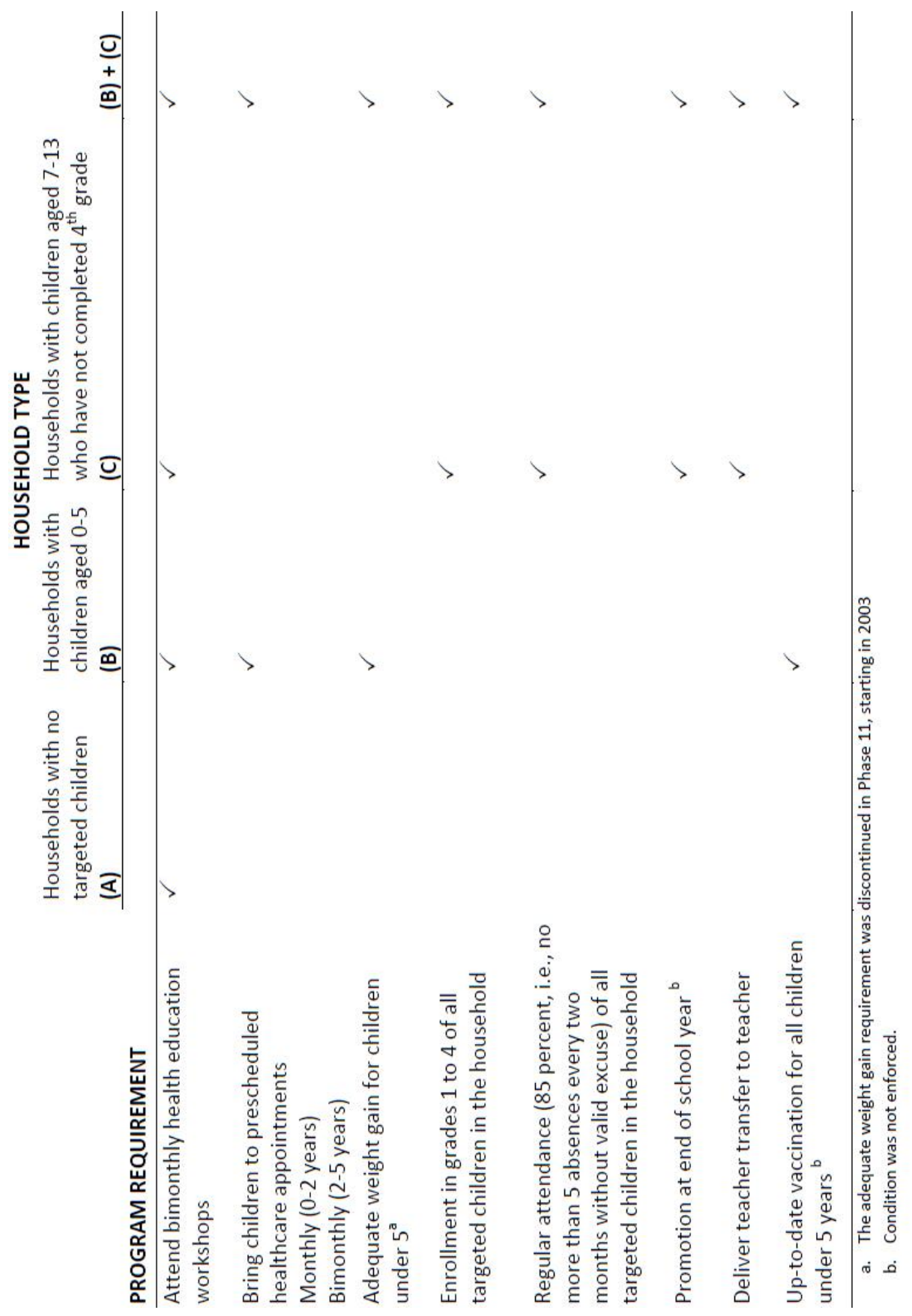

Figure 1: RPS Eligibility and Requirements. Source: Maluccio and Flores 2005 
Nicaraguan RPS eligibility and benefits in Phase 1

\begin{tabular}{|c|c|c|}
\hline \multicolumn{3}{|c|}{ Program components } \\
\hline & Food security, health and nutrition & Education \\
\hline \multicolumn{3}{|l|}{ Eligibility } \\
\hline Geographic targeting & All households & $\begin{array}{l}\text { All households with children } \\
\text { aged 7-13 who have not } \\
\text { completed fourth grade of } \\
\text { primary school }\end{array}$ \\
\hline \multicolumn{3}{|l|}{ Demand-side benefits } \\
\hline \multirow[t]{2}{*}{ Monetary transfers } & $\begin{array}{l}\text { Bono alimentario } \\
\text { (food security transfer) } \\
\text { C\$2,880 per household per year } \\
\text { (US\$224) }\end{array}$ & $\begin{array}{l}\text { Bono escolar } \\
\text { (school attendance transfer) } \\
C \$ 1,440 \text { per household per } \\
\text { year } \\
\text { (US\$112) }\end{array}$ \\
\hline & & $\begin{array}{l}\text { Mochila escolar } \\
\text { (school supplies transfer) } \\
\text { C\$275 per child beginning of } \\
\text { school year } \\
\text { (US\$21) }\end{array}$ \\
\hline \multicolumn{3}{|l|}{ Supply-side benefits } \\
\hline $\begin{array}{l}\text { Services provided and } \\
\text { monetary transfers }\end{array}$ & $\begin{array}{l}\text { Health education workshops } \\
\text { every } 2 \text { months } \\
\text { Child growth and monitoring } \\
\text { Monthly: Newborn to } 2 \text {-year-olds } \\
\text { Every } 2 \text { months: } 2 \text { - to } 5 \text {-year-olds } \\
\text { Provision of antiparasite medicine, } \\
\text { vitamins, and iron supplements } \\
\text { Vaccinations (newborn to 5-year- } \\
\text { olds) }\end{array}$ & $\begin{array}{l}\text { Bono a la oferta } \\
\text { (teacher transfer) } \\
\text { C } \$ 80 \text { per child per year given } \\
\text { to teacher/school (US\$6) }\end{array}$ \\
\hline
\end{tabular}

Figure 2: RPS Transfers. Source: Maluccio and Flores 2005

of household characteristics.

A household with multiple eligible children $i=1 \ldots n$, has utility $U$ a function of $C$ representing nonmedical consumption, health status of each child $H$, a binary indicator of school enrolment $S$, with $S=1$ indicating school enrolment, and an indicator of gender $g$. The household maximisation problem is then:

$$
\max _{C, H, S} U\left(C, H_{i}, S_{i} ; g\right)
$$

The time constraint for a school component eligible child can be written as:

$$
T_{i}=T_{s i} . S_{i}+T_{w i}\left(1-S_{i}\right)
$$

where $T_{s i}$ is time spent in school and is assumed to be a fixed amount for all enrolled children, $T_{w i}$ is time spent at work. 
The money budget constraint of the household can be written as:

$$
C+\sum_{i=1}^{n} \delta_{i} \cdot S_{i}+p_{m} \cdot M-\mu \cdot E^{m}=Y+\sum_{i=1}^{n} w \cdot T_{w i}\left(1-S_{i}\right)
$$

Where $\mu \cdot E^{m}=0$ in the pre-program scenario, $\delta_{i}$ is the direct cost of schooling for child $i$. Primary schooling in free in Nicaragua and most children face no tuition fees, hence $\delta_{i}$ includes all other school related costs faced by families such as transport, uniforms, books and school meals. $p_{m}$ is the cost per unit of medical care consumed and $Y$ is household income net of the earnings of the program eligible children. With $\mu . E^{m}=0$ in the pre-program scenario the money budget constraint is:

$$
C+\sum_{i=1}^{n} \delta_{i} \cdot S_{i}+p_{m} \cdot M=Y+\sum_{i=1}^{n} w \cdot T_{w i}\left(1-S_{i}\right)
$$

The constrained household maximisation problem is:

$$
\max _{C, H, S, T_{w}, T_{s}} U\left(C, H_{i}, S_{i} ; g\right)
$$

which is maximised subject to a full income constraint that combines the time constraint of school going children and the money budget constraint of the household:

$$
C+\sum_{i=1}^{n}\left[\delta_{i}+w \cdot T_{s i}\right] S_{i}+p_{m} \cdot M=Y+w \cdot \sum_{i=1}^{n} T_{i}=F
$$

$F$ is full income of the household. The full income constraint expresses the total price of schooling for all eligible children in the family $\left(\theta=\sum_{i=1}^{n}\left[\delta_{i}+w \cdot T_{s i}\right]\right)$ as the costs of schooling plus the shadow wage for the eligible children.

Optimising the utility with respect to the constraints gives the standard reduced form demand functions for the outcomes of interest - schooling $S^{*}=\Phi\left(F, \theta, p_{m}, n ; g, X_{h}\right)$ and health is $H^{*}=\Omega\left(F, \theta, p_{m}, n ; g, X_{h}\right)$

The RPS program has two cash transfers - the first focuses on changing the price of schooling for eligible children conditional on enrolment and the second is a food transfer meant to boost consumption, nutrition and access to preventive health care conditional on mothers' attending the health workshops. The initial objective of RPS was to condition the food transfer on a series of other requirements including taking children under 5 years for health checks and maintaining up-to-date immunization. But as explained in the program description these conditionalities were not enforced till almost the second year of the program and hence does not affect the analysis in this paper. The household food transfer $(\mu)$ conditional on $E_{m}$ is modelled as 
a direct income effect, raising the income level of the household and does not stipulate specific expenditure categories. At subsistence consumption levels, an increase in income through a transfer is assumed to impact food consumption changing consumption patterns to more nutritious components in the food basket and reducing financial barriers to utilizing preventive care. The focus on health checks and immunization as outcomes without their being implemented as a conditionality is useful in analysing the short-term impact of increased economic status on accessing child health services.

The school transfer is implemented as two components $(\tau, \rho)$ to reduce the net price of schooling and substitute for any wages earned by children not enrolled in school due to employment. Schooling and labour market participation are assumed in the model to be substitutes. A decrease in the price of schooling is likely to encourage children to substitute away from labour market participation and increase school enrolment. The first component $\tau$ is provided for each eligible child in the family while $\rho$ is a lump sum transfer irrespective of the number of eligible children. Both transfers are conditional on all eligible children enrolling in school.

With the introduction of the subsidies $\mu . E^{m}, \tau \cdot \sum_{i=1}^{n} S_{i} . S_{p}$ and $\rho . S_{p}$, where $S_{p}=1$ if $\sum_{i=1}^{n} S_{i}=n$ ie. all eligible children enrol in school and $S_{p}=0$ otherwise, the full income for a beneficiary family is:

$$
C-\rho . S_{p}-\mu \cdot E^{m}+\sum_{i=1}^{n}\left(\delta_{i}+w \cdot T_{s i}-\tau . S_{p}\right) S_{i}+p_{m} \cdot M=Y+\sum_{i=1}^{n} w \cdot T_{i}=\tilde{F}
$$

The new price of schooling under the subsidy program is $\tilde{\theta}=\left(\sum_{i=1}^{n}\left[\delta_{i}+w \cdot T_{s}-\tau \cdot S_{p}\right]\right)$ and the new level of full income is $\widetilde{F}$. The optimal choice under the subsidies is $S^{* *}=\Phi\left(\tilde{F}, \tilde{\theta}, p_{m}, n ; g, X_{h}\right)$ and health is $H^{* *}=\Omega\left(\tilde{F}, \tilde{\theta}, p_{m}, n ; g, X_{h}\right)$

Identifying the ex ante impact of the program using the approach of **toddandwolpin10 requires the health outcomes reduced form demand function $H$ (and school outcomes function $S$ ) to remain the same before and after the program is introduced i.e

$$
H^{* *}=\Omega\left(F, \theta, p_{m}, n ; g, X_{h}\right)=\Omega\left(\tilde{F}, \tilde{\theta}, p_{m}, n ; g, X_{h}\right)
$$

The above equation shows that the reduced form functions before and after the program are the same except for the magnitudes of the exogenous policy variables. This assumes that the program has an influence only through the budget constraint and does not directly enter the utility function. Empirically this allows exploitation of two sources of variation in the data to compare untreated individuals with outcomes $H^{*}$ with other untreated individuals with outcomes $H^{* *}$ - the first is school costs and the second is full income of the 


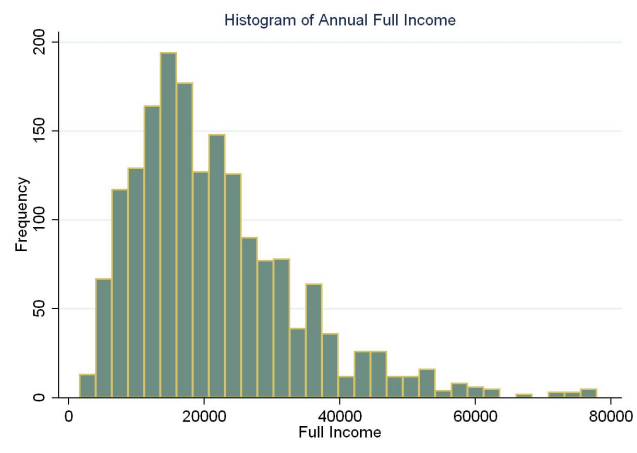

(a) Household Expenditure

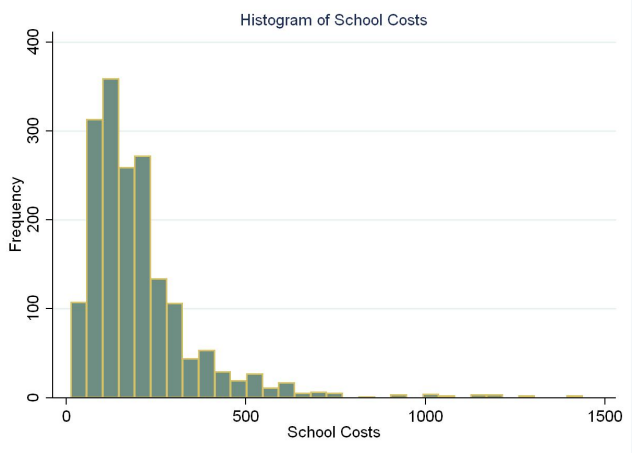

(b) School Costs

Figure 3: Data Variation

households at the baseline. As described earlier, primary education is free in Nicaragua and most families face no fees, the cost here includes other expenditure related to schooling which is exogenous in the sense that it is faced by all families when enrolling children irrespective of whether the tuition is free or not. Figure 3(a) shows a histogram of full income of families, with values ranging from c1,590 to c77,905. The second graph figure 3(b) shows the school costs used in the estimation, which range from c12 to c1438. In addition to variation in school costs and full income, the level of the school grant also varies depending on the number of children in the household. The treatment effect is estimated by matching untreated individuals with other untreated individuals on functions of observable characteristics. Identifying the ex ante treatment effect also requires that any unobserved heterogeneity $(\nu)$ remains the same before and after treatment ie. $(\nu)$ is independent of full income and school costs. To make this assumption plausible, empirically the matching functions include a set of family characteristics.

$$
f(\nu \mid F, \theta)=f\left(\nu \mid \tilde{F}, \tilde{\theta}, X_{h}\right)
$$

\section{Empirical Specification}

The behavioural model reduced form approach proposed by Todd \& Wolpin (Forthcoming) exploits exogenous variation in the policy related variables (in this paper full income and school costs) at the baseline and matches untreated individuals on functions of observable characteristics. The estimator they propose is broadly analogous to an ex post matching estimator set in the potential outcomes framework (?Rubin 1974). An ex post matching evaluation uses information on both treated outcomes $\left(H_{1}\right)$ and untreated outcomes $\left(H_{0}\right)$ from a suitable comparison group and matches individuals on observable characteristics where the 
average outcomes for the matched untreated individuals is the counterfactual for the average outcomes for the treated group if they had not been treated (Heckman et al. 1997). In the case of the ex ante evaluation the outcomes of the treated group $\left(H_{1}\right)$ are unobserved and must be estimated from the observed $\left(H_{0}\right)$ untreated/baseline information. This translates to estimating:

$$
H_{1 i}=E\left[H_{0 j} \mid F_{i}=\widetilde{F_{j}}, \theta_{i}=\widetilde{\theta}_{j}, p_{m i}=p_{m j}, n_{i}=n_{j}, g_{i}=g_{j}, X_{h i}=X_{h j}\right]+\epsilon
$$

The estimator proposed by Todd \& Wolpin (Forthcoming) for the ex ante evaluation estimates the average treatment effect for those eligible for the program (intent-to-treat (ITT)) as:

$\alpha=\frac{1}{k} \sum_{j=1}^{k}{ }_{j, i \in S_{p}} E\left(H_{i} \mid F_{i}=\widetilde{F_{j}}, \theta_{i}=\widetilde{\theta}_{j}, p_{m i}=p_{m j}, n_{i}=n_{j}, g_{i}=g_{j}, X_{h i}=X_{h j}\right)-H_{j}\left(F_{j}, \theta_{j}, p_{m j}, n_{j}, g_{j}, X_{h j}\right)$

\subsection{Estimating School Costs}

Implementing the above matching estimator requires estimation of the unobserved treated outcomes as a function of household expenditure, school costs, medical care expenditure and a set of household characteristics. School costs $\left(\delta_{i}\right)$ are determined by the enrolment status of the child and hence are observed in the data for only those children who are currently enrolled in school and zero costs observed for those not enrolled. The problem of predicting school costs for the entire sample of children requires using a two-step process decomposing the participation decision and the determinants of the cost of schooling. A two-part model (2PM) is applied where in the first part, the enrolment decision, is modelled using a probit and the second part predicts the cost of schooling as a linear function of the determinants of school costs (Mullahy 1998). The most common specification of the second part is a log transformation of the outcome variable. A problem with using a retransformed OLS in this case is that zero school costs are also observed in the sample of those children currently attending school. A log transformation would drop these observations from the estimation sample. A further problem arises with retransformation of the outcome variable to the original scale in the presence of heteroskedasticity. Manning (1998) shows that heteroskedasticity leads to biased estimates of the outcome variable and correction requires determining whether the heteroskedasticity is across different groups or caused by a particular subset of the covariates. To overcome these issues the second part of the $2 P M$ is estimated using the extended estimating equations model (EEE) proposed by Basu \& Rathouz (2005). The EEE approach is a semi-parametric extension of a standard generalized linear 
model $(G L M)$ incorporating flexible link and variance functions. It has two main advantages it identifies an appropriate link function from the data enabling identification of an underlying model for the error distribution and when no particular distribution can be identified from the outcome variable it serves as a robust estimator. Specifically, the EEE combines a Box-Cox transformation for the link function and includes a class of link functions represented by an estimated parameter $\lambda$ :

$$
\begin{array}{lll}
\frac{\mu^{\lambda}-1}{\lambda} & \text { if } & \lambda \neq 0 \\
\log (\mu) & \text { if } & \lambda=0
\end{array}
$$

It also allows for heteroskedasticity and uses a general power function for the variance defined by twoparameters $\theta_{1}$ and $\theta_{2}$ :

$$
V(y)=\theta_{1} \mu^{\theta_{2}}
$$

The model is estimated separately for boys and girls.

\subsection{Estimating Counterfactual Outcomes}

The unobserved binary outcomes $E\left(H_{i} \mid F_{i}=\widetilde{F_{j}}, \theta_{i}=\widetilde{\theta_{j}}, p_{m i}=p_{m j}, n_{i}=n_{j}, g_{i}=g_{j}, X_{h i}=X_{h j}\right)$ are estimated using Klein and Spady's (Klein \& Spady 1993) semiparametric estimator. The estimator belongs to the class of non-parametric single index models with conditional probability $P(H=1 \mid X=x)=G(x \beta)$ but where the distribution function $G$ is left unspecified. The estimator is semiparametric in the sense that the only nonparmetric component of the estimator is the linear index $G(x \beta)$ while the $x$ 's maintain a linear specification as in the parametric counterpart of a probit or logit. The semiparametric single index specification offers several advantages over a fully nonparmetric approach, it allows for as many covariates as required by the model by eliminating the curse of dimensionality problem where the model's convergence rates are inversely proportionate to the number of covariates. It also offers greater regions of support for predictions as compared to a nonparametric model by extending the region of support beyond the observed $x$ to points not in the support of $x$ but in the support of $x \beta$ (Horowitz 1998).

Klein and Spady adapted single index models for binary outcomes, the index function is defined as:

$$
E(H \mid x)=P(H=1 \mid x)=G(x \beta)
$$


The estimator, like more general single index models, involves two unknowns - $\beta$ and $G$. Estimation of both elements require several identification restrictions. Similar to all linear models, identification of $\beta$ requires $G$ to be a non-constant function along with the absence of multicollinearity amongst the covariates. In addition, to uniquely identify the function $G(x \beta)$ single-index models involve location normalization and scale normalization restrictions. Location normalization is achieved by requiring the covariate vector to include no intercept term while scale normalization involves restricting the $\beta$ coefficient of one continuous variable to equal one. Identification in single-index models is achieved because the conditional mean function can remain constant with changes in $x$ as long as the index $x \beta$ remains constant. However, with continuous covariates a constant index (ie. $x \beta=k$ ) for a given set of covariates has probability zero. To overcome this a further identification restriction is required where $G$ is a differentiable function so that $G(x \beta)$ is close to $G(k)$ when $x \beta$ is close to $k$ Horowitz (1998). A final set of restrictions are required when $X$ contains both discrete and continuous variables. The first of these requires that the discrete elements of the covariate vector do not divide the support of $x \beta$ into disjoint subsets. The final restriction is referred to as the 'non-periodicity condition' for the function $G$ requiring it to be strictly increasing.

Klein and Spady's adaptation of single index models for binary outcomes uses maximum likelihood estimation(MLE) where the log-likelihood is:

$$
\ln L\left(\beta, G_{n}\right)=n^{-1} \sum_{i=1}^{n}\left[H_{i} \ln G_{n}\left(x_{i} \beta\right)+\left(1-H_{i}\right) \ln \left(1-G_{n}\left(x_{i} \beta\right)\right)\right]
$$

The difference from a parametric estimator such as probit or logit is that $G_{n}\left(x_{i} \beta\right)$ is a semiparametric likelihood estimate which is estimated using a leave-one-out nonparametric estimator of the density of $x \widehat{\beta}$ conditional on $H$, where for any $z$

$$
G_{n}\left(x_{i} \beta\right)=\frac{P_{n} g_{n}(z \mid H=1)}{P_{n} g_{n}(z \mid H=1)+\left(1-P_{n}\right) g_{n}(z \mid H=0)}
$$

where $g_{n}$ is the kernel estimate of the conditional density of $x \beta(g(. \mid H))$ and $g_{n}$ is defined as:

$$
\begin{gathered}
g_{n}(z \mid H=1)=\frac{\sum_{i=1}^{n} H_{i} K\left(z-x_{i} \widehat{\beta}\right) / h_{n}}{n P_{n} h_{n}} \\
g_{n}(z \mid H=0)=\frac{\sum_{i=1}^{n}\left(1-H_{i}\right) K\left(z-x_{i} \widehat{\beta}\right) / h_{n}}{n\left(1-P_{n}\right) h_{n}}
\end{gathered}
$$

where $P_{n}$ is the empirical probability $P_{n}=\sum_{i=1}^{n} H_{i}$, the proportion of infants taken to a health check in 
the last six months or the proportion with full coverage immunization. $K$ is a kernel function and $h_{n}$ is the bandwidth.

Klein and Spady show that the estimator is asymptotically efficient and achieves the semiparametric efficiency bounds of Chamberlain (1986) and Cosslett (1987). The resulting vector of parameter estimates $(\hat{\beta})$ is shown to have the following properties:

$$
\begin{gathered}
n^{1 / 2}(\widehat{\beta}-\beta) \longrightarrow_{d} N(0, \Omega) \\
\Omega=E\left\{\left[\frac{\partial G\left(X_{i} \beta\right)}{\partial \beta}\right]\left[\frac{\partial G\left(X_{i} \beta\right)}{\partial \beta}\right]^{T}\left[\frac{1}{G\left(X_{i} \beta\right)\left(1-G\left(X_{i} \beta\right)\right)}\right]\right\}^{-1} \\
E\left(H_{i} \mid F_{i}=\widetilde{F}_{j}, \theta_{i}=\widetilde{\theta}_{j}, p_{m i}=p_{m j}, n_{i}=n_{j}, g_{i}=g_{j}, X_{h i}=X_{h j}\right) \text { (unobserved treated outcomes for health }
\end{gathered}
$$
checks and FCV) are estimated using the semiparametric estimator described above. Each of the unobserved outcomes is estimated using a different model specification. They include the basic household characteristics - education and gender of the household head, composition of the household, school costs and full wealth and age of the child. In addition the model for health checks includes two community level characteristics that serve as opportunity costs of accessing care - distance to the nearest health facility and distance to the nearest public transport facility. In estimating the model for full coverage of vaccination predicted outcomes are compared with Barham \& Maluccio (2009) who estimate two versions of the experimental outcome - one including community variables and the other without. They find both give similar results. The estimation in the paper is a model without community level characteristics and hence includes only the household and child characteristics described above.

Scale normalization is achieved by setting the coefficient for years of education for the household head equal to 1 . The estimated models are then used to first predict outcomes for the observed control (baseline) group observations and then extrapolate the predictions under treatment by evaluating the function at $(\tilde{F}, \tilde{\theta}){ }^{1}$

The above specifications are also used for simulating alternate policy scenarios for both the health outcomes and school enrolment. For the simulation of school enrolment the model consists of the same household and child characteristics described earlier and include variables for distance to the nearest primary and secondary schools, whether the household lives in a coffee growing community and distance to the nearest public

\footnotetext{
${ }^{1}$ The statistical package np (Hayfield \& Racine 2008 ) available for the software $\mathrm{R}$ was used. The scalar bandwidth for the index $x \beta$ for the health checks model is 0.037 and for the FCV model is 0.077 .
} 
transport facility. The enrolment models are estimated separately for boys and girls and jointly for different age groups.

Both within sample predictions and extrapolation can only be carried out in regions of common support. In the original formulation of the model Klein and Spady trim the likelihood function (12 to ensure that $G$ is bounded away from 0 and 1. Simulations of their model and other studies using this estimator (Horowitz 1993, Gerfin 1996, Fernández \& Rodríguez-Poo 1997) find little impact of trimming in empirical applications. Following these studies this application does not trim the likelihood function. Extrapolation in nonparametric models is only valid at points with positive data density. The region of support $S_{p}$ in the semiparametric model is defined as $S_{p}=(x \beta) \in R^{2}$ such that $f(x \beta) \geq 0$ where $f(x \beta)$ is the nonparmetric density of the linear index. ${ }^{2}$ Heckman et al. (1997) propose that the density should be strictly positive as defined by $S_{p}$ and should exceed a minimum cut-off to avoid points with very low density. Thus the extrapolation is valid for only those points of evaluation where

$$
f(x \hat{\beta})>c
$$

Heckman et al. (1997) recommend setting the cut-off at a percent quantile of the estimated densities. Here $c$ is set at the $2 \%$ quantile. Only those observations that meet the above criterion are kept in the extrapolation sample.

\section{Data and Variables}

The ex ante evaluation is carried out using data from the randomized pilot evaluation of RPS. As part of the experiment data was collected in four rounds. The first, a census survey of chosen localities in May/June 2000, this was followed by a comprehensive baseline for all members of the treatment and control groups, followed by follow-up surveys in October 2001 and October 2002. This ex ante evaluation uses data from the census and baseline surveys for the estimation and compares the predicted outcomes with those observed using the first follow-up survey. A total of 1581 households were included in the experiment.

The estimation sample consists of 576 households with children aged 0-3 who were eligible for the food security, health and nutrition component of the program. Of this sample 353 households also had children between ages 7-13 who had not completed grade 4 of primary school and were hence eligible for the school transfer as well.

\footnotetext{
${ }^{2}$ The densities are estimated using the method of Li \& Racine (2003) who use 'generalized product kernels' for mixed data. The bandwidths were set using maximum likelihood cross validation
} 
The census survey collected basic information on living conditions and the distance to the nearest school for each household and at individual level, information on education and school enrolment, land ownership and work. The baseline and follow-up surveys collected detailed information on the same categories and in addition the baseline survey had a detailed module on health and health related variables for all members of the household. These surveys however did not gather information on income and different sources of income but instead collected information on complete household expenditure and asset ownership.

\subsection{Dependent variables}

The ex ante impact is estimated for two health related variables - health checks and full coverage of vaccinations (FCV). In the randomized experiment parents of all children below 5 years in the household were asked whether the child had been taken for a health check in the last six months. The estimation of predicted impact focuses on children below 3 years with a balanced (households observed in the baseline and follow-up survey) sample size of 792. At the baseline just over 70 percent of children in this age group had been taken to a health check within the last 6 months.

The full coverage of vaccination variable was constructed following the approach in Barham \& Maluccio (2009), using a series of questions on different vaccines. The baseline survey recorded the number of doses each child received since birth for the following set of vaccines (1) tuberculosis vaccine (BCG) (2) measles containing vaccine (MCV) or measles-mumps-rubella (MMR) vaccine (3) oral polio vaccine (OPV) (4) diphtheria-pertussis-tetanus vaccine (DPT) or pentavalent vaccine (or both). The international recommendation for up-to-date time of vaccination is $<12$ months and $12-23$ months of age depending on the vaccine. A child is considered fully vaccinated if it receives all the required doses within the specified time period. Table 1 gives the schedule for recommended vaccinations. A binary variable for FCV was constructed equal to one if a child's vaccine schedule was up-to-date and zero otherwise. The estimation was restricted to children 12-23 months of age to be sure that all children had a chance to receive the BCG vaccine which is scheduled for below 12 months. The total sample size of the balanced sample is 281 .

A second objective of this paper is to evaluate alternate policy scenarios. These simulations are carried out for both the schooling outcomes as well as the two health related variables described above. The main policy variable considered for the school outcome is the enrolment rate. Households with children between ages 7-13 who had not completed grade 4 of primary school were eligible for the school transfer conditional on all children in the household enrolling and maintaining $85 \%$ attendance. The enrollment outcome is also a binary variable equal to one if an eligible child enrols and zero otherwise. The estimation sample consists 
Table 1: Basic vaccination schedule for up-to-date vaccinations

\begin{tabular}{lccc}
\hline Disease & Vaccine & Dose & Recommended age \\
\hline Tuberculosis & BCG & 1 & At birth \\
Measles & MCV & 1 & 12 months \\
Polio & OPV & 3 & $2,4,6$ months \\
Diphtheria-pertussis-tetanus & DPT & 3 & $2,4,6$ months \\
\hline \multicolumn{4}{c}{ Source:Barham \& Maluccio (2009) }
\end{tabular}

of 1786 program eligible children.

\subsection{Explanatory variables}

The estimation of the unobserved outcomes under treatment is driven by the reduced form equations from the theoretical model. The policy enters the model through an impact on the budget constraint and changes two key variables in the reduced form - school costs (for families with children eligible for the school transfer) and full wealth (for all families). The baseline surveys provide information on total household expenditure and asset ownership which are together used as a proxy for full wealth. The second policy variable - school costs is however observed only for those children aged 7-13 who are currently enrolled in school and have to be estimated for the those who are eligible but not enrolled. For those families in the sample without children eligible for the school component school costs remain zero.

The schools costs are estimated using variables that capture direct and opportunity costs, set of household and child characteristics and family wealth. The census survey provides information on the education of the household head and distance to the nearest primary school (used as a measure of opportunity cost of travel time). These variables are mapped to the baseline survey. The baseline survey provides all the other variables. Family characteristics include - household expenditure and asset ownership, age, gender and years of schooling completed by the household head, number of children of school going age, number of adults in the household and number of children under 5 years. To avoid problems of endogeneity, household wealth (expenditure plus assets) is included net of the school costs.

The unobserved outcomes $E\left(H_{i} \mid F_{i}=\widetilde{F_{j}}, \theta_{i}=\widetilde{\theta}_{j}, p_{m i}=p_{m j}, n_{i}=n_{j}, g_{i}=g_{j}, X_{h i}=X_{h j}\right)$ for health checks and FCV are estimated using the variables generated by the reduced form of the behavioural model. These include, household characteristics - education and gender of the household head, composition of the household, school costs and full wealth and age of the child, distance to the nearest health facility and distance to the nearest public transport facility (for the health checks model). The simulations of alternate 
policy scenarios also use the same specifications.

\section{Results}

\subsection{Estimating School Costs}

Table 2 shows the results from estimating the two part model for boys and girls. The probit participation model for both boys (1) and girls (3) show a similar patter, with enrolment being most likely between the ages of 8 and 10 as compared to children aged 7 (reference category)and declining with older children. Boys drop out earlier (above age 10) while girls aged 13 are less likely to enrol when compared to the reference group. This pattern follows most developing countries where many children enrol and stay in school only for a few years, dropping out between the ages of 11-13 to find employment. Household expenditure net of school costs (used as a proxy for income) and education of the household head are significant and have a positive impact on enrolment. As mentioned earlier the probit model includes the number of children under 5 years as a proxy for child labour. The estimates show similar negative magnitudes for boys and girls indicating having younger children in the household decreases the likelihood of enrolment. A similar effect of distance to the nearest school is observed, with children being less likely to enrol if schools are further away. Enrolment probabilities differ for boys and girls depending on the gender and the employment status of the head of the household. Girls are less likely to enrol if a male is head of the household, as is the case in $88 \%$ of the households in the sample. The direction of the coefficient for employment status is less intuitive as boys seem less likely to enrol if the household head is employed. This result is probably due to the nature of employment, with about $85 \%$ of the sample being involved in farm activities. The last two variables though not significant in the model do indicate the presence of a gender gap from additional opportunity costs for boys and cultural differences that contribute to the differences in schooling.

Columns (2) and (4) of Table 1 provide results from the second part of the two part model using the extended estimating equations model (EEE) (Basu \& Rathouz 2005) for school costs ${ }^{3}$. Boys in the reference category (age 7) face the highest school costs. At other ages there is no significant impact on school costs. For girls however, school costs increase with age. Families with greater wealth (household expenditure) tend to spend more on education, although more on the boys than the girls. In both cases children of the same

\footnotetext{
${ }^{3}$ An alternative approach to the EEE model would be to use a generalized linear model with a specified link function and distribution. However, failure to specify the correct link function results in misspecification of the model. To avoid such misspecifications, the EEE approach was used since it does not require an a priori assumption of a link function or distribution. This approach 'helps to identify an appropriate link function and to suggest an underlying distribution for a specific application but also serves as a robust estimator when no specific distribution for the outcome measure can be identified' Basu \& Rathouz (2005).
} 
Table 2: Estimating School Costs

\begin{tabular}{|c|c|c|c|c|}
\hline VARIABLES & $\begin{array}{c}\text { (1) } \\
\text { Probit-Boys } \\
\text { Enrollment }\end{array}$ & $\begin{array}{c}(2) \\
\text { EEE-Boys } \\
\text { School Costs }\end{array}$ & $\begin{array}{c}\text { (3) } \\
\text { Probit-Girls } \\
\text { Enrollment }\end{array}$ & $\begin{array}{c}\text { (4) } \\
\text { EEE-Girls } \\
\text { School Costs }\end{array}$ \\
\hline age8 & $\begin{array}{c}0.116 \\
(0.151)\end{array}$ & $\begin{array}{c}0.117 \\
(0.139)\end{array}$ & $\begin{array}{l}0.251 \\
(0.160)\end{array}$ & $\begin{array}{c}0.168 \\
(0.103)\end{array}$ \\
\hline age9 & $\begin{array}{c}0.265 \\
(0.161)\end{array}$ & $\begin{array}{c}0.180 \\
(0.147)\end{array}$ & $\begin{array}{c}0.544^{* *} \\
(0.168)\end{array}$ & $\begin{array}{c}0.385^{* * *} \\
(0.103)\end{array}$ \\
\hline age10 & $\begin{array}{c}0.174 \\
(0.164)\end{array}$ & $\begin{array}{l}0.0439 \\
(0.124)\end{array}$ & $\begin{array}{l}0.285 \\
(0.172)\end{array}$ & $\begin{array}{l}0.345^{*} \\
(0.172)\end{array}$ \\
\hline age11 & $\begin{array}{c}-0.00216 \\
(0.164)\end{array}$ & $\begin{array}{l}0.0458 \\
(0.133)\end{array}$ & $\begin{array}{c}0.202 \\
(0.179)\end{array}$ & $\begin{array}{c}0.470^{* * *} \\
(0.116)\end{array}$ \\
\hline age12 & $\begin{array}{c}-0.00164 \\
(0.172)\end{array}$ & $\begin{array}{c}0.189 \\
(0.137)\end{array}$ & $\begin{array}{c}0.147 \\
(0.188)\end{array}$ & $\begin{array}{c}0.523 * * \\
(0.197)\end{array}$ \\
\hline age13 & $\begin{array}{c}-0.554^{* * *} \\
(0.168)\end{array}$ & $\begin{array}{l}0.0256 \\
(0.138)\end{array}$ & $\begin{array}{l}-0.159 \\
(0.198)\end{array}$ & $\begin{array}{r}0.205 \\
(0.134)\end{array}$ \\
\hline HH Exp (adjusted) & $\begin{array}{c}0.0000116^{* *} \\
(0.00000447)\end{array}$ & $\begin{array}{c}0.0000405^{* * *} \\
(0.00000345)\end{array}$ & $\begin{array}{c}0.0000122^{*} \\
(0.00000593)\end{array}$ & $\begin{array}{c}0.0000264^{* * *} \\
(0.00000359)\end{array}$ \\
\hline School dist & $\begin{array}{c}-0.00703^{* * *} \\
(0.00178)\end{array}$ & $\begin{array}{c}0.00346^{* *} \\
(0.00118)\end{array}$ & $\begin{array}{c}-0.00806^{* * *} \\
(0.00173)\end{array}$ & $\begin{array}{r}0.00230 \\
(0.00155)\end{array}$ \\
\hline No. of adults & $\begin{array}{r}-0.0336 \\
(0.0328)\end{array}$ & & $\begin{array}{r}0.0536 \\
(0.0413)\end{array}$ & \\
\hline Children under5 & $\begin{array}{c}-0.172^{* *} \\
(0.0550)\end{array}$ & $\begin{array}{c}-0.224^{* * *} \\
(0.0398)\end{array}$ & $\begin{array}{c}-0.228^{* * *} \\
(0.0621)\end{array}$ & $\begin{array}{l}-0.0780 \\
(0.0430)\end{array}$ \\
\hline Children 7-13 & $\begin{array}{c}0.0814 \\
(0.0463)\end{array}$ & $\begin{array}{c}-0.258^{* * *} \\
(0.0443)\end{array}$ & $\begin{array}{l}-0.0462 \\
(0.0557)\end{array}$ & $\begin{array}{c}-0.240^{* * *} \\
(0.0391)\end{array}$ \\
\hline HHH gender & $\begin{array}{r}0.335 \\
(0.183)\end{array}$ & & $\begin{array}{l}-0.0755 \\
(0.198)\end{array}$ & \\
\hline $\mathrm{HHH}$ age & $\begin{array}{c}0.00714 \\
(0.00529)\end{array}$ & & $\begin{array}{c}0.00979 \\
(0.00562)\end{array}$ & \\
\hline $\mathrm{HHH}$ yrs of ed & $\begin{array}{l}0.106^{* *} \\
(0.0381)\end{array}$ & & $\begin{array}{l}0.180 * * * \\
(0.0436)\end{array}$ & \\
\hline HHH works & $\begin{array}{c}-0.0949 \\
(0.173)\end{array}$ & & $\begin{array}{r}0.186 \\
(0.194)\end{array}$ & \\
\hline Constant & $\begin{array}{l}-0.0227 \\
(0.325) \\
\end{array}$ & $\begin{array}{c}-0.377^{*} \\
(0.155) \\
\end{array}$ & $\begin{array}{r}-0.0752 \\
(0.375) \\
\end{array}$ & $\begin{array}{c}-0.288^{*} \\
(0.131) \\
\end{array}$ \\
\hline$\lambda$ & & $\begin{array}{l}0.289^{*} \\
(0.143)\end{array}$ & & $\begin{array}{c}0.663^{* *} \\
(0.204)\end{array}$ \\
\hline$\theta_{1}$ & & $\begin{array}{l}1.242^{* * *} \\
(0.0887)\end{array}$ & & $\begin{array}{c}1.564^{* * *} \\
(0.157)\end{array}$ \\
\hline$\theta_{2}$ & & $\begin{array}{c}1.597 * * * \\
(0.106)\end{array}$ & & $\begin{array}{c}1.737^{* * * *} \\
(0.111)\end{array}$ \\
\hline Observations & 945 & 687 & 845 & 631 \\
\hline
\end{tabular}

Robust standard errors in parentheses, clustered at the household level

*** $\mathrm{p}<0.01,{ }^{* *} \mathrm{p}<0.05,{ }^{*} \mathrm{p}<0.1$ 


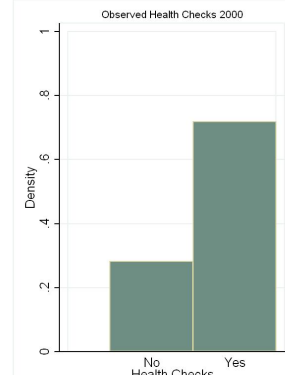

Noath Checks Yes

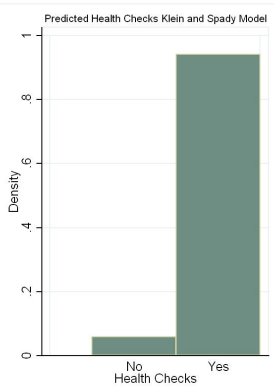

(a) Observed Baseline (2000) Outcomes and Predicted Outcomes for Health Checks
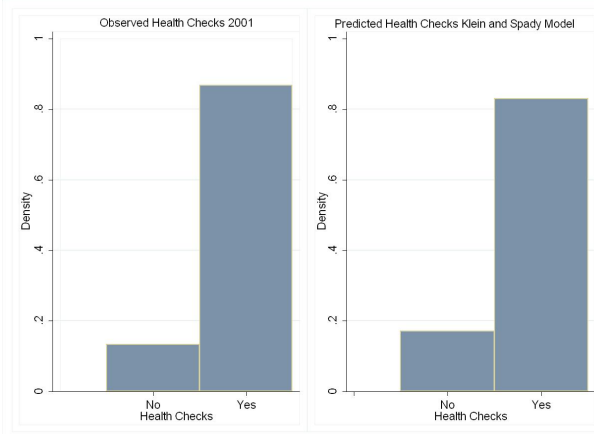

(b) Observed Outcomes (2001) and Predicted Outcomes for Health Checks
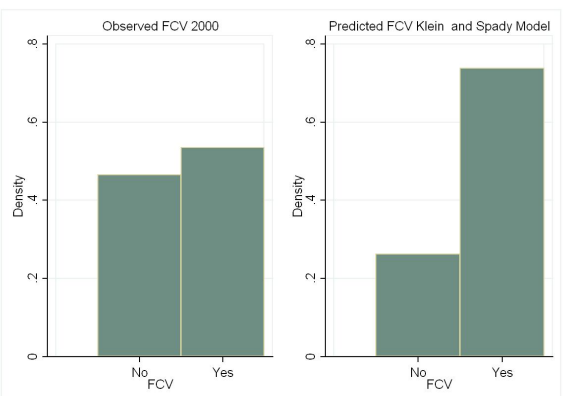

(c) Observed Baseline (2000) Outcomes and Predicted Outcomes for FCV
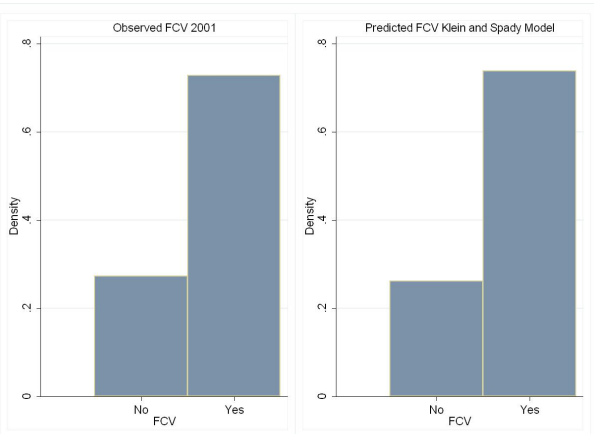

(d) Observed Outcomes (2001) and Predicted Outcomes for FCV

Figure 4: Comparing Observed and Predicted Outcomes

age and children under five is significant (except for girls -children under5) and negative. This is intuitive in the sense that sharing of resources reduces the costs per child as the number of school age children increases.

In Column (2) for the boys sample the link parameter is estimated to be $\lambda=0.289$ (95\% C.I: 0.01, 0.57). The variance function represented by $\theta_{1}=1.2\left(95 \%\right.$ C.I:1.07 ,1.42) and $\theta_{2}=1.6(95 \%$ C.I:1.39, 1.80$)$ is close to a gamma distribution. Column (4) provides the estimates for the sample of girls. In this case with $\lambda=0.66(95 \%$ C.I: $0.26,1.06)$, the link function is close to a square root link. The values $\theta_{1}=1.5(95 \%$ C.I:1.26,1.87) and $\theta_{2}=1.74(95 \%$ C.I:1.51, 1.95) again suggest a gamma distribution.

\subsection{Predicting Impact}

The counterfactual (unobserved) health related outcomes after program implementation $\left(H^{* *}=\Phi\left(\tilde{F}, \tilde{\theta}, p_{m}, n, g ; X_{h}\right)\right)$ are estimated using the Klein and Spady binary estimator described in section IV(b). The health checks model is specified as a function of education and gender of the household head, composition of the house- 

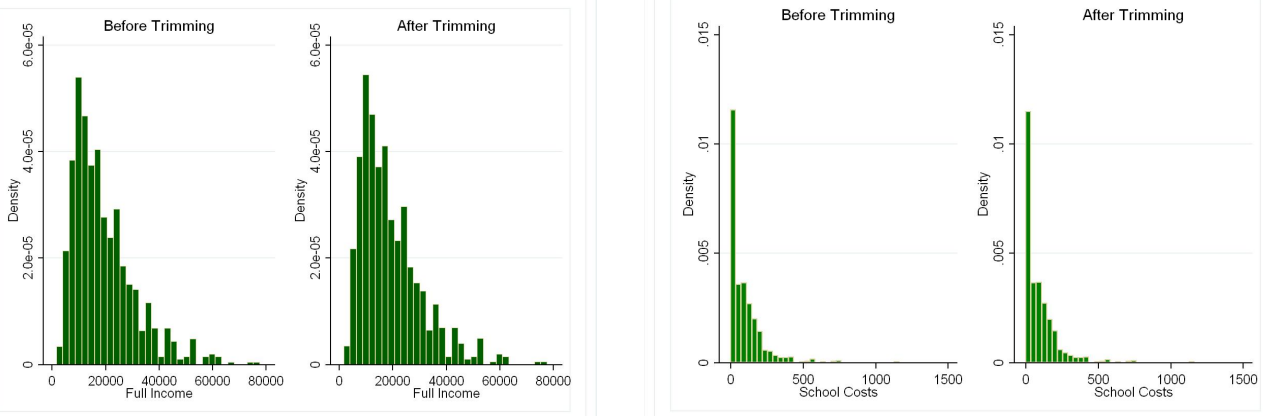

(a) Household Expenditure

(b) School Costs

Health Checks Estimation
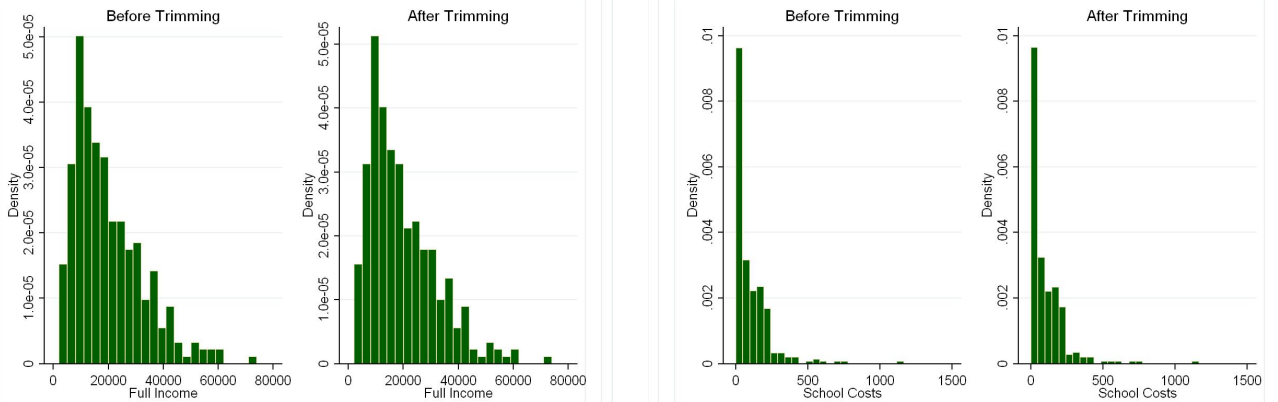

(c) Household Expenditure

(d) School Costs

\section{FCV Estimation}

Figure 5: Trimming Klein and Spady estimations

hold, estimated school costs and full wealth (net of education and health expenditure) of the household after adjusting for the income transfer, and age of the child. Figure 4(a) compares the observed baseline outcomes $\left(H_{j}\right.$ in equation 11$)$ with the predicted impact from the Klein and Spady model $\left(H_{i}\right.$ in equation 11$)$. The figure shows a large increase in the estimated proportion of children being taken to health checks with the cash transfer program. To see how close the predicted outcomes under treatment are to the observed outcomes under treatment, figure 4(b) compares the Klein and Spady predictions with the data from the 2001 follow-up survey. The figure shows that the predicted impact from the model is very close to the observed survey data with evidence of slight underprediction.

Figures 4(c) and 4(d) show similar graphs for the FCV model. The model predicts very closely the unobserved outcomes in 2001 (figure 4(d)). A comparison with data from the follow-up survey shows two very similar graphs. When compared to the baseline, the cash transfer induces a significant increase in the proportion of children under 2 years who have up-to-date immunizations. 
The predictions from the estimator (equation 11) are only valid in the region of common support defined by equation 16 . Figures 5(a),5(b),5(c)and 5(d) compare the distributions of the policy variables before and after trimming at $2 \%$ quantile of the density of the linear index $(f(x \hat{\beta}))$. The graphs show that observations with very low density - concentrated at the extreme right tail of the distributions are eliminated. Intuitively this means that families with very high houshold expenditure or school costs where no suitable matches could be found are dropped from the estimated treatment effect.

Conditional cash transfers provide a social policy tool that combine improvement in child health with education outcomes for school eligible children. The cash transfers are typically accompanied by a package of health related conditionalities relating to preventive care. But combining both does not allow separation of different pathways ie. the impact of the cash transfer separate from the conditionality. The RPS program was also designed as a combination of three factors - a school enrolment transfer, a food security transfer and a series of conditionalities relating to child health. The health services at the scheduled visits included growth monitoring, provision of vaccinations and nutritions supplements. But as described in the program description the RPS program for the first 8 months of the program these health services were not provided nor any conditionalities enforced relating to the health/food security transfer. The impacts for the first year are then largely the impact of the cash transfer in improving utilization of health services without the conditionalities.

Table 3: Predicted Impact

\begin{tabular}{|c|c|c|c|}
\hline OUTCOMES & $\begin{array}{c}\text { (1) } \\
\text { Predicted Impact }\end{array}$ & $\begin{array}{c}(2) \\
\text { Sample sizes }^{@}\end{array}$ & $\begin{array}{c}(3) \\
\text { Experimental impact }\end{array}$ \\
\hline Health Checks & $0.22^{* * *}$ & $779 / 792$ & $0.24^{* * *}$ (1 year) \\
\hline (children below 3 years) & $(0.0250)$ & & \\
\hline FCV & $0.20 * * *$ & $275 / 281$ & $0.20^{* *}(1$ year $)$ \\
\hline (Children below 2 years) & $(0.0451)$ & & \\
\hline
\end{tabular}

Table 3 shows the one year predicted impacts for the two preventive healthcare utilization outcomes and compares them with the double difference estimates from the experimental evaluation. Column (1) reports the results from the Klein and Spady estimates, column (2) provides the sample size before and after trimming the predicted outcomes and column (3) gives the experimental estimates. The impacts in this table are for the balanced sample defined as observing a household in both the baseline and follow-up 
survey. The ex ante model predicts closely the outcome of health checks in the last six months for children below 3 years, with one year of cash transfers resulting in a .22 increase as compared to a .24 increase in the experimental evaluation. The table also reports the one year impact of on-time full coverage of immunization for children between 12 and 23 months of age. The ex ante result shows a statistically significant .20 increase in FCV which perfectly predicts the results from the experimental evaluation. These results demonstrate that it may be possible to improve utilization of preventive services in low income households without implementing conditionalities on their usage. Of particular interest is the immunization outcome which in the RPS design is not a pre-requisite for receiving the cash transfer. An improvement in household income encourages households to invest in child health. Other studies have found similar results of cash transfers or income increases leading to improvements in child health. Fernald et al. (2008) disaggregate the ex post impact of cash transfers in Mexico's Oportunidades (Progresa) program from other aspects of the program. They hold constant the conditionalities as required by the program and analyse the impact of increases in the cash transfer. Since in Progresa the conditionalities for preventive health were enforced rigorously from the beginning they look at direct health outcomes such as stunting and find improvements in child health from larger transfers. ${ }^{4}$

Comparing the ex ante results to the experiment provides a way of validating the model used. The validated models are then used to simulate alternate policy scenarios. Two alternate policy formulations are estimated using the validated models, the first estimates the impact of reducing the total cash transfer amount to $75 \%$ of the original program while continuing to maintain the conditionalities. Both cash transfers, the school transfer and food security/health transfer are reduced to $75 \%$ of the original amount. The per child component of the school transfer is also reduced similarly. The results of this scenario are reported in column (2) of table 4. The second scenario estimated is that of providing a transfer equal to the value of the food transfer. This component has two aspects, first the conditionality on enrolment is removed ie. school costs are no longer adjusted but secondly, the conditionality for receipt of the transfer ie. mothers attending health workshops continues. This is how the original program was modeled except that there is no school component of the transfer. As mentioned earlier the conditionalities on accessing preventive care were not enforced in the first 8 months. The estimated impacts can provide an insight into how households are likely to allocate resources between preventive health care for young children and education of older children. The results of the second simulation exercise are reported in column (3) of table 4 . In both cases the estimated results are compared to the experimental results (column 1) from the original program design. The last

\footnotetext{
${ }^{4}$ Case et al. (2002) also find evidence that children in families with higher income have better health outcomes.
} 
Table 4: Simulating Counterfactual Policy Scenarios

\begin{tabular}{|c|c|c|c|c|}
\hline OUTCOMES & $\begin{array}{l}(1) \\
\text { Experimental } \\
\text { Impact }\end{array}$ & $\begin{array}{l}(2) \\
75 \% \text { of origi- } \\
\text { nal }\end{array}$ & $\begin{array}{l}(3) \\
\text { Unconditional } \\
\text { transfer } \\
(\mathrm{c} 2880)\end{array}$ & $\begin{array}{l}(4) \\
\text { Sample sizes }\end{array}$ \\
\hline \multicolumn{5}{|c|}{ Health related outcomes } \\
\hline Health Checks & $0.24^{* * *}$ & $\begin{array}{l}0.22^{* * *} \\
(0.0264)\end{array}$ & $\begin{array}{l}0.21^{* * *} \\
(0.0277)\end{array}$ & $779 / 792$ \\
\hline FCV & $0.20^{* * *}$ & $\begin{array}{l}0.21^{* * *} \\
(0.0431)\end{array}$ & $\begin{array}{l}0.12^{* * *} \\
(0.0427)\end{array}$ & $275 / 281$ \\
\hline & Scho & enrolment ou & comes & \\
\hline Boys $7-13$ & $0.19 * * *$ & $\begin{array}{l}0.19^{* * *} \\
(0.0207)\end{array}$ & $\begin{array}{l}0.17^{* * *} \\
(0.0209)\end{array}$ & $859 / 876$ \\
\hline Girls $7-13$ & $0.20^{* * *}$ & $\begin{array}{l}0.20^{* * *} \\
(0.0224) \\
\end{array}$ & $\begin{array}{l}0.16^{* * *} \\
(0.0169)\end{array}$ & $754 / 767$ \\
\hline Boys \& Girls $<10$ & $0.23^{* * *}$ & $\begin{array}{l}0.16^{* * *} \\
(0.0239) \\
\end{array}$ & $\begin{array}{l}0.12^{* * *} \\
(0.0263) \\
\end{array}$ & $829 / 844$ \\
\hline Boys \& Girls $>=10$ & $0.15^{* * *}$ & $\begin{array}{l}0.14^{* * *} \\
(0.0123)\end{array}$ & $\begin{array}{l}0.17^{* * *} \\
(0.0153)\end{array}$ & $786 / 799$ \\
\hline
\end{tabular}

@ treatment observations after trimming, total number of observations.

Bootstrapped standard errors clustered at the comarca level (500 reps).

$* * * \mathrm{p}<0.01,{ }^{* *} \mathrm{p}<0.05,{ }^{*} \mathrm{p}<0.1$

column of table 4 reports the sample sizes for the models before and after trimming.

Comparing column (1) and column (2) of table 4 shows that reducing the amount of the transfer to $75 \%$ of the original amount has little impact on the preventive care utilization outcomes. Health checks increase by .22 as compared to .24 in the original program while FCV shows a 1 percentage point increase from .20 to .21. The price effect of the school transfer is equally strong when reduced to $75 \%$. Overall boys and girls show similar outcomes from the reduced cash transfer scenario as they did under the original program. For boys aged 7-13 both the original program and the reduced cash transfer show a .19 increase in school enrolment. The simulation for the sample of girls shows a 1 percentage point increase from .20 to .21. Similar results are evident when looking at enrolment by age groups. The same specification was used for the models for boys and girls and the different age groups. A point of concern here is the predicted impact for boys and girls below 10. The predicted impact under the alternate policy scenario shows only a .16 increase in enrolment as compared to .23 from the experimental outcome. Some caution is required in interpreting this result as the ex ante model of the orignal program underpredicts the impact. ${ }^{5}$ The estimated impact for the

\footnotetext{
${ }^{5}$ The ex ante estimation of the original progam shows a statistically significant .17 increase in enrolment for children below 10 years. Results for all the other age groups are statistically significant and almost identical to the experiment: boys .19, girls
} 
reduced cash transfer is very close to the estimated ex ante result from the original policy design. In general a reduction to $75 \%$ while maintianing the conditionality for the school component has important budget implications for the program. The price effect from reducing school costs by conditioning enrolment can be achieved with a lower level of transfer. Even at the lower level of the transfer families access preventive care at the same rate as the original program specification.

To test the importance of the conditionality of the school transfer and its implications for other components of the household's behaviour the validated model is used to estimate the impact of a transfer equal to just the food security/health component with no adjustment of school costs, thus relaxing the enrolment conditionality. Column (3) in table 4 reports the estimated impacts which are quite different from both the experimental results and the policy scenario with $75 \%$ of the transfers and the conditionalities. School enrolment for both boys and girls is lower by 3 percentage points. More interestingly there is a large reduction in enrolment for children below 10 (.12 increase from the baseline) and a rise in enrolment for children above age 9 years ( 2 percentage point increase). The biggest difference is in the proportion of children who receive on-time full coverage of vaccinations, the unconditional transfer results only in a .12 increase from the baseline while taking children for health checks shows a 3 percentage point decline when compared to the experimental impact. One plausible explaination for the sharp decline in enrolment amongst younger children and in the health outcomes is that without a compulsory enrolment requirement for all children aged 7-13, parents now have to choose between enrolling older or younger children. The school sample consists of children who have not completed grade 4 of primary school. In the short term parents seem to invest in the enrolment of the older children while delaying enrolment for the younger children. Also, the cash transfers are meant to subsitute for the wages earned by the children enabling the family to have them enrol in school. In the short term with a fixed budget constraint parents seem to compromise accessing preventive care, particularly ensuring up-to-date vaccinations for infants, and enroling younger children for an extra year of education for older children who are less likely to complete further education if they delay enrolment further. The idea of the food transfer in addition to providing a school transfer was to improve nutrition and remove financial barriers to accessing health care. This however does not appear to be the pathway with just a cash transfer with no conditionality on schooling. Particularly for immunizations a strong income effect emerges with greater income levels resulting in higher rates of child immunizations. However, to improve investment in child health and school enrolment the conditionalities seem critical, particularly to ensure enrolment of younger children is not compromised for education of older children. ${ }^{6}$ Todd \& Wolpin (Forthcoming) also .21 , children 10 years and over .15 .

${ }^{6}$ Simulations with just the school enrolment component - with conditionalities shows results almost identical to the those of 
find for the Progresa program that conditionalities are necessary to have an impact on enrolment, although in their sample they study older children (ages 12-15).

\section{Conclusion}

This paper applies the methods proposed by Todd \& Wolpin (Forthcoming) to estimate ex ante, the impact of Nicaragua's conditional cash transfer program Red de Protección Social. This approach relies on reduced form estimation of the impact by matching untreated individuals on functions of observable characteristics. Identification of the impact relies on variation in the variables related to the policy being evaluated, in this case school costs and full wealth. A simple household model of school enrolment and investment in child health is used to derive the reduced forms that are empirically estimated. The approach is used to estimate the impact of the cash transfer on accessing preventive care for children i.e taking children below 3 years to health checks and full coverage of vaccinations for children between 12-23 months. Empirically the model is implemented using a semi-parametric single index framework that allows for an increase in the dimensionality of the covariate vector. The outcomes are binary and the semi-parametric estimator proposed by Klein and Spady is used to predict the unobserved outcomes under treatment. The data set combines baseline data from the RPS experiment along with some information from the census survey . The baseline data is used as a single cross-section combining both control and treatment groups. The estimated ex ante impact is validated against results from the randomized experiment. These models are then used to simulate two policy scenarios that differ from the original program in the amount of the transfer and the conditionality. These simulations are carried out for both school enrolment (children aged 7-13 years) and preventive health care utilization for younger children.

In general the estimated impacts all have the same direction as the experiment. The model performs well in predicting the magnitude of the impact for the two health related outcomes. An improvement in household income increases a households' investment in child health. The two policy simulations show interesting results. The first simulation maintains the school related conditionality of the program but reduces both cash transfer components by $75 \%$. The estimations show little difference in most of the categories from the original program. The price effect from reducing school costs by conditioning enrolment can be achieved with a lower level of transfer as can similar levels of preventive care utilization. The second simulation of an unconditional cash transfer equal to the amount of just the food security component shows a strong income ex ante model for the original program specification. 
effect for immunizations and is accompanied by change in enrolment patterns, with higher enrolment levels for older children but at the cost of delays in enroling younger children. 


\section{References}

Attanasio, O., Meghir, C. \& Santiago, A. (2005), Education choices in mexico: using a structural model and a randomized experiment to evaluate progresa, Open access publications from university college london, University College London.

URL: http://ideas.repec.org/p/ner/ucllon/http-eprints.ucl.ac.uk-14750-.html

Barham, T. \& Maluccio, J. A. (2009), 'Eradicating diseases: The effect of conditional cash transfers on vaccination coverage in rural nicaragua', Journal of Health Economics 28(3), 611-621.

URL: http://ideas.repec.org/a/eee/jhecon/v28y2009i3p611-621.html

Basu, A. \& Rathouz, P. J. (2005), 'Estimating marginal and incremental effects on health outcomes using flexible link and variance function models', Biostat 6(1), 93-109.

Behrman, J. R. \& Wolfe, B. L. (1987), 'How does mother's schooling affect family health, nutrition, medical care usage, and household sanitation?', Journal of Econometrics 36(1-2), 185-204.

URL: http://ideas.repec.org/a/eee/econom/v36y1987i1-2p185-204.html

Brooker, S., Hall, A. \& Bundy, D. (1999), 'Short stature and the age of enrolment in primary school: studies in two african countries', Social Science 83 Medicine 48(5), 675 - 682.

URL: http://www.sciencedirect.com/science/article/B6VBF-3VKD1V8-8/2/a13fab1f033bbb6b25dc8fa3f8b6be7c

Case, A., Lubotsky, D. \& Paxson, C. (2002), 'Economic status and health in childhood: The origins of the gradient', The American Economic Review 92(5), 1308-1334.

URL: $h t t p: / / w w w . j s t o r . o r g / s t a b l e / 3083252$

Chamberlain, G. (1986), 'Asymptotic efficiency in semi-parametric models with censoring', Journal of Econometrics 32(2), 189-218.

URL: http://ideas.repec.org/a/eee/econom/v32y1986i2p189-218.html

Cosslett, S. R. (1987), 'Efficiency bounds for distribution-free estimators of the binary choice and the censored regression models', Econometrica 55(3), 559-585.

Engle, P. L., Black, M. M., Behrman, J. R., Cabral de Mello, M., Gertler, P. J., Kapiriri, L., Martorell, R., Young, M. E. \& the International Child Development Steering Group (2007), 'Strategies to avoid the 
loss of developmental potential in more than 200 million children in the developing world', The Lancet 369(9557), 229-242.

Ensor, T. \& Cooper, S. (2004), 'Overcoming barriers to health service access: influencing the demand side', Health Policy and Planning 19(2), 69-79.

URL: http://heapol.oxfordjournals.org/cgi/content/abstract/19/2/69

Fernald, L. C. H., Gertler, P. J. \& Neufeld, L. M. (2008), 'Role of cash in conditional cash transfer programmes for child health, growth, and development: an analysis of mexicos oportunidades', The Lancet 371, 828-37.

Fernández, A. I. \& Rodríguez-Poo, J. M. (1997), 'Estimation and specification testing in female labour participation models: Parametric and semiparametric methods', Econometric Reviews 16(2), 229-247.

Gerfin, M. (1996), 'Parametric and semi-parametric estimation of the binary response model of labour market participation', Journal of Applied Econometrics 11(3), 321-339.

Glassman, A., Todd, J. \& Gaarder, M. (2007), Performance-based incentives for health: Conditional cash transfer programs in latin america and the caribbean, Working Papers 120, Center for Global Development. URL: http://ideas.repec.org/p/cgd/wpaper/120.html

Glewwe, P., Jacoby, H. G. \& King, E. M. (2001), 'Early childhood nutrition and academic achievement: a longitudinal analysis', Journal of Public Economics 81(3), 345 - 368.

URL: http://www.sciencedirect.com/science/article/B6V76-43GH12C-1/2/07a43a0cda39fr77d624dc50c0126b96a

Grantham-McGregor, S., Cheung, Y. B., Cueto, S., Glewwe, P., Richter, L. \& Strupp, B. (2007), 'Developmental potential in the first 5 years for children in developing countries', The Lancet 369(9555), 60 - 70. URL: $h t t p: / / w w w . s c i e n c e d i r e c t . c o m / s c i e n c e / a r t i c l e / B 6 T 1 B-4 M R G V D 0-14 / 2 / f 7 b e 2638 b 42 c 35417 f 70 f 3 b 4 a d 4348 c 2$

Hadler, S. C. (2004), Vaccination programs in developing countries, Vaccines, 4 edn, Philadelphia, PA: Elsevier Inc, chapter 55.

Hayfield, T. \& Racine, J. S. (2008), 'Nonparametric econometrics: The np package', Journal of Statistical Software 27(5).

URL: http://www.jstatsoft.org/v27/i05/

Heckman, J. J., Ichimura, H. \& Todd, P. E. (1997), 'Matching as an econometric evaluation estimator: Evidence from evaluating a job training programme', Review of Economic Studies 64(4), 605-54. 
Horowitz, J. L. (1993), 'Semiparametric estimation of a work-trip mode choice model', Journal of Econometrics 58(1-2), 49-70.

Horowitz, J. L. (1998), Semiparametric methods in econometrics, New York: Springer-Verlag.

Ichimura, H. \& Taber, C. R. (2000), Direct estimation of policy impacts, NBER Technical Working Papers 0254, National Bureau of Economic Research, Inc.

URL: $h t t p: / /$ ideas.repec.org/p/nbr/nberte/0254.html

Klein, R. W. \& Spady, R. H. (1993), 'An efficient semiparametric estimator for binary response models', Econometrica 61(2), 387-421.

Li, Q. \& Racine, J. (2003), 'Nonparametric estimation of distributions with categorical and continuous data', Journal of Multivariate Analysis 86(2), 266-292.

Maluccio, J. A. \& Flores, R. (2005), Impact evaluation of a conditional cash transfer program: the nicaraguan red de proteccin social, Research reports 141, International Food Policy Research Institute (IFPRI).

URL: http://ideas.repec.org/p/fpr/resrep/141.html

Manning, W. G. (1998), 'The logged dependent variable, heteroscedasticity, and the retransformation problem', Journal of Health Economics 17(3), 283 - 295.

Miller, M. A. \& Hinman, A. R. (2004), Economic analyses of vaccine policies, Vaccines, 4 edn, Philadelphia, PA: Elsevier Inc, chapter 57.

Moock, P. R. \& Leslie, J. (1986), 'Childhood malnutrition and schooling in the terai region of nepal', Journal of Development Economics 20(1), 33 - 52 .

URL: http://www.sciencedirect.com/science/article/B6VBV-46RVBX4-V/2/03829e3fffabc79e1615747cf57a4617

Mullahy, J. (1998), 'Much ado about two: reconsidering retransformation and the two-part model in health econometrics', Journal of Health Economics 17(3), 247 - 281.

]neymanetal1923 Neyman, J. (1923[1990]), 'On the application of probability theory to agricultural experiments. essay on principles. section 9.', Statistical Science 5(4), 465-472. Trans. Dorota M. Dabrowska and Terence P. Speed.

URL: http://www.jstor.org/stable/2245382 
Rubin, D. B. (1974), 'Estimating causal effects of treatments in randomized and non-randomized studies.', Journal of Educational Psychology 66, 688-701.

Strauss, J. \& Thomas, D. (2008), Health over the Life Course, Vol. 4 of Handbook of Development Economics, Elsevier, chapter 54, pp. 3375-3474.

URL: http://ideas.repec.org/h/eee/devchp/5-54.html

Todd, P. E. \& Wolpin, K. I. (2006), 'Assessing the impact of a school subsidy program in mexico: Using a social experiment to validate a dynamic behavioral model of child schooling and fertility', American Economic Review 96(5), 1384-1417.

URL: http://ideas.repec.org/a/aea/aecrev/v96y2006i5p1384-1417.html

Todd, P. E. \& Wolpin, K. I. (Forthcoming), 'Ex ante evaluation of social programs', Annales d'Economie et de Statistiques . 